\title{
Sciendo
}

\section{De Bello Robotico. An Ethical Assessment of Military Robotics}

\author{
Riccardo Campa \\ Jagiellonian University, \\ Cracow, Poland \\ e-mail: riccardo.campa@uj.edu.pl
}

\begin{abstract}
:
This article provides a detailed description of robotic weapons and unmanned systems currently used by the U.S. Military and its allies, and an ethical assessment of their actual or potential use on the battlefield. Firstly, trough a review of scientific literature, reports, and newspaper articles, a catalogue of ethical problems related to military robotics is compiled. Secondly, possible solutions for these problems are offered, by relying also on analytic tools provided by the new field of roboethics. Finally, the article explores possible future developments of military robotics and present six reasons why a war between humans and automata is unlikely to happen in the 21 st century.

Keywords: military robotics, unmanned systems, drones, combat robots, ethical problems, roboethics.
\end{abstract}

\section{Defining Robotic Weapon}

Military robotics is a relatively recent phenomenon, and a conventional agreement upon terminology does not yet exist. Therefore, the preliminary praxis in every scientific work, namely to clarify the terms and concepts, is even more necessary in the present context. In US military and political circles ${ }^{1}$ the term-concept 'unmanned system' has been introduced to denote systems of weaponry that do not require the presence of human beings where they are located. Such systems are piloted (remote-piloted) at a distance by human beings, and even - in the most evolved systems - endowed with greater or lesser autonomy to decide and act. So they are referred to as 'unmanned systems' to distinguish them from 'manned systems,' that is systems without a human operator as distinguished from systems with a human operator. In addition, journalists prefer to use more suggestive expressions such as 'war robot' or 'robot soldier,' even if on closer examination these terms are only used to refer to the more advanced and therefore controversial 'unmanned systems,' that is, those that are of some interest to the press.

In this work we have decided to use the expression 'unmanned system' (UM) as the generic term to refer to any systems of robotic weapon with a military use. We also regard the expressions 'military robots' or 'robot weapons' as being literally equivalent to UM, while the term 'robot soldier' refers only to especially advanced weapons systems, the kind that have some decisionmaking capabilities, and built for authentic combat.

For a long time, the United States have been compiling and making public a collection of documents with the title Unmanned Systems Roadmap that takes stock of the situation on the 
features and uses of the military weapons currently available to the army and tracks the future development of these weapon systems over the next twenty-five years. We have roadmaps published on a biennial basis (2005-2030, 2007-2032, 2009-2034, 2011-2036, 2013-2038, 20152040, 2017-2042, etc.). The last versions have been called Unmanned Systems Integrated Roadmap, because they attempt to integrate the different aspects of the construction and the use of military robots from the point of view of their interoperability. Priority was given to independent accounts and blueprints of the different typologies of military robots that were worked out and then 'added together.

The Office of the Secretary of Defense Unmanned Systems Roadmap (2007-2032) does not give a precise definition of unmanned systems, but a definition of an unmanned vehicle - the element that constitutes its main component - hints at the meaning. Here is the definition proposed by the document:

Unmanned Vehicle. A powered vehicle that does not carry a human operator, can be operated autonomously or remotely, can be expendable or recoverable, and can carry a lethal or nonlethal payload. Ballistic or semi-ballistic vehicles, cruise missiles, artillery projectiles, torpedoes, mines, satellites, and unattended sensors (with no form of propulsion) are not considered unmanned vehicles. Unmanned vehicles are the primary component of unmanned systems" [8, p. 1].

So, as well as a positive definition, the vehicle is also given a negative definition, which rules out a whole range of technological products used in war: ballistic vehicles, missiles, artillery projectiles, torpedoes, mines, satellites, static sensors. Positively, these vehicles are ones with their own type of propulsion, that leaves out the human operator, that can act autonomously or be remote controlled, can be reused many times, and can carry a lethal or nonlethal load. They can in fact carry surveillance systems (video cameras, radars, sonars, microphones, etc.) or lethal weapons (cannons, machine guns, missiles, rockets, etc.). The system of a military weapon is defined by the entire vehicle - its form, propulsion system, dimensions, weight, velocity, etc. - and by the load it carries - its electronic brain, its sensors, its weapons, etc. - that together define its belligerent function.

\section{Robots of the Sky, the Sea, and the Land}

The various editions of the Unmanned System Integrated Roadmap offer a large catalogue (albeit incomplete) of robotic weapons systems. Mind that we will not speak about the technical features of every single model, but only of the best known ones. Best known since they have had the honour of media attention precisely because they are ethically controversial in some way or other.

To begin, unmanned systems are divided into three major groups depending on where they are being deployed: in the air, on land, in water. We therefore have unmanned systems equipped for air warfare (UAS - Unmanned Aircraft System), for ground warfare (UGV - Unmanned Ground Vehicle) and for naval warfare (UMV - Unmanned Maritime Vehicle). The latter subdivide in their turn into two categories: Above Water (USV - Unmanned Surface Vehicle) and submarines (UUV - Unmanned Undersea Vehicle). Researchers have renamed UAS as 'flying robots' or 'drones,' a term whose origin is related to the shape of these aircrafts [44], [34], [26].

Also the press has noticed the proliferation of these military robots, as a recent report in an Italian daily attests:

Bang, a target is hit, no soldiers employed. This is the evolution of defence systems that on-going wars do much to accelerate. Recognition, attack, transportation, tracking and rescuing are tasks more and more frequently given to robots, which paves the way for the automatized warfare prefigured in science fiction movies. Under the generic appellation of Unmanned Systems, these weapons, that function without a human pilot, 
were first in use in aviation and have now been fitted inside motorboats, helicopters and motor vehicles [12].

The article reports that the first 'drone' was used by Israel in the Yom Kippur war, and that sixty years of incessant warfare combined with a cutting edge high tech industry have made Israel the leading nation in the development and production of unmanned weaponry, "surpassing the gutsy US military industry and the land of robotics, Japan." For the sake of precision, it is necessary to recall that "remotely piloted aircraft first appeared during World War I" [48, p. 4]. Remote controlled aircraft were also used by the Americans in the forties, when they tested the effects of the first nuclear bombs. This of course does not intend to diminish Israel's remarkable technological work in the field.

So the article continues:

During the first Gulf War, in 1991, the Air Force had about a hundred drones; today it is deploying 7000 and keeps churning out new models in response to a demand that knows no limits. This race against the clock is to blame for the high number of accidents: 100 times the number of those involving manned aircrafts according to a study by the Congress. 2009 was the year of the watershed: US aviation trained more pilots in front of a screen with a joystick than in the cockpit holding the control stick. Fewer victims, less expensive to train, but surely more frustrating for Top Gun aspirers.

The article states that there are about forty nations that are developing UM technology. As regards the Italian contribution, it mentions the efforts by Alenia Aeronautica, holder of the patents of SkyX and of SkyY, in addition to taking part in the nEUROn program for the construction of a European unmanned military aircraft and in the Molynx program, the goal of which is the development of a high-altitude robotic twin-motor with up to 30 hours autonomy.

The main goal of the revolution of unmanned vehicles, on land or in the air - the article continues - is that of decreased risk to soldiers. But it is also to contribute, a little like satellites in space, to the complex virtual network of sensors and communications that extend across the stage of operations. Add to this considerations of an economic nature: the take-down of a drone, that flies in any weather, is the equivalent of throwing 45 millions dollars down the drain, if it is a jet fighter 143 millions, naturally not counting the human loss. The US armed force aims for the creation of a fleet of unmanned vehicles equal to a third of the total before 2015. Market valuations predict that turnover in the UM sector may reach 5 billion euros in Europe between 2010 and 2020, and double in the ten years after that and arrive at a total global level of 45 billion euros by 2030 .

The article clearly shows one important implication of this new robotic arms race: even if Western nations are at the forefront today, military robots are not the prerogative of these nations, and everything leads one to think that in the future wars will be fought more and more exclusively by machines. More than ever before they will be wars of technology and of industrial systems. Indeed, guerrilla warfare also bets on the potentialities of military robots, so much so that in the Lebanese conflict of 2006 Hezbollah launched 4 drones, the fruit of Iranian technology, on Israeli locations.

Finally, one should keep in mind all the negative and positive repercussions (depending on one's point of view) that the development of military technology has always had on civilians. Even when they are conceived of as systems of weaponry, drones are not limited to military uses. Unpiloted aircrafts are used for the relief work in the case of natural catastrophes and to enforce law and order. For example, the US Coast Guard uses them. New York Air National Guard navy is endowed since 2008 with Predator, an unmanned aircraft nine meters long already used in the war in Yugoslavia. Some models were also in use in Italian skies, on the occasion of the G8 Summit held in Aquila. Remote controlled aircrafts surveyed the crowds spotting turmoil or demonstrators who tried to break into the red zones. "Also the KMax, the unmanned helicopter of Lockheed and 
Kaman, is increasingly used to transport gear for the troops, as well as for the transportation of special goods to high altitudes and to intervene in forest fires" [12].

Yet the article by la Repubblica mainly focuses on Israel. According to this newspaper, 10 or 15 years from now at least a third of the vehicles in use by the armed forces will consist of UM. Guardium, an armoured vehicle designed by GNius to patrol the borders with Lebanon and Gaza, came into use at the beginning of 2009. It is a small Jeep, similar to a golf cart, fitted with completely automatic command, control and navigation systems. Since last year civilians and the army in the occupied territories have begun using remote-controlled bulldozer convoys to resupply. Rexrobot, a six-wheel vehicle with the carrying capacity of $200 \mathrm{~kg}$ of goods to follow the infantry susceptible to receive and execute vocal commands is currently undergoing evaluation in the Israel Defence Forces. Soon will be launched high-velocity unmanned vessels designed by Rafael Industries, with a rigid shell and an inflatable cockpit. The motorboat Protector USV, called Death Shark, is equipped with 4 ultra high definition panoramic cameras (which can capture details 10 miles away) able to shoot in 3D, sonar systems, electro-optical sensors, and remote laser-controlled machine guns able to fixate the target even in rough sea.

What these machines contribute to dangerous demining operations is also fundamental. Many robot models have been designed to explore mined areas and to spot the contrivances. Since mines too evolve - for instance they are now made of synthetic materials that escape the metal detector - the robot's sensory apparatus must similarly evolve to spot these lethal contrivances. For example,

there are the mine sniffers, that the robotics laboratory of the University of Brescia is currently working on, that use 'artificial noses' pegged to entirely autonomous structures that will recognize the smell of the explosive just like dogs. Researchers in Lausanne have tackled the problem of rough terrain by equipping the mine-seeking robot with mountain bike style wheels fitted with crampons to 'escalate' rocky ground. Today some models even work on solar power [12].

The picture given by this newspaper, even though not always precise and even though it deals exclusively with the Middle East, is detailed and informed enough. Reading the Roadmap by the American Department of Defense tells us that the United States pursue the goal of the robotization of the armed forces with a determination no lesser than that shown by Israel. Innumerable prototypes and models are (or have been) produced and used. Here we shall limit ourselves to giving a few examples of each type, in order to give a feel for the technological level that has been reached or that one wants to reach in the future.

\subsection{Sky Robots}

"An unmanned aircraft system (UAS) is a 'system whose components include the necessary equipment, network, and personnel to control an unmanned aircraft.' In some cases, the UAS includes a launching element" [46, p. 4].

As regards robotized military aircrafts, one model that unquestionably deserves looking into is the MQ-1 Predator, produced by General Atomics Aeronautical Systems, Inc. In use by all three American armed forces, in 2007120 specimens were delivered, 95 available and 170 commissioned. Since 1995 the Predator has completed missions of reconnaissance and surveillance in Iraq, Bosnia, Kosovo and Afghanistan. In 2001, the US air force fitted Predator with a laser designator to guide ammunition with high precision and enabled it to deploy Hellfire missiles. As a result of these modifications, the machine became multifunctional, that is capable of both combat and reconnaissance. The upgraded version (MQ-1) completed 170,000 flight hours (as of July 2006), of which a good $80 \%$ had been in combat. Today the machine has been taken out of service.

Various 'successors' or models developed from the Predator have already been produced by the same company. One of these is the MQ-9 Reaper. In 2009, the inventory of the Roadmap 2009- 
2034 states that 18 specimens have been delivered and 90 planned. A few years later, the Roadmap 2013-2038 confirms that 112 vehicles of this type are in service (as of July 1,2013), and provides a detailed case study of this machine which "illustrates the strategy and actions required, when proper initial lifecycle sustainment planning was not done, to transform the sustainment of unmanned systems from a short-term, rapid-fielding environment to a long-term sustainment environment" [46, pp. 142-144].

The MQ-9 Reaper is a robotic aircraft able to operate at medium altitude, with very high flight autonomy (up to 24 hours). As regards the mission, the priorities have been reversed. This system is primarily a hunter-killer system for critical targets, thanks to electro-optical devices and laser-steered bombs or missiles, with only a secondary role given to the system used in intelligence, reconnaissance and surveillance.

One of the systems adopted by the USAF for high altitude reconnaissance and long flight autonomy is the RQ-4 Global Hawk by Northrop Grumman Corporation (12 machines delivered and 54 planned in 2009, 35 in service in 2013). It is capable of monitoring an area of 40,000 nautical square miles per day, at a maximum altitude of 65,000 feet and with autonomy of up to 32 hours. Surveillance is entrusted to very advanced systems, first tested in 2007: Advanced Signals Intelligence Program (ASIP) and Multi-Platform Radar Technology Insertion Program (MP-RTIP).

Nevertheless, if the principal requirement is to keep the 'spy' flying for many days, without needing to return to base, even for daily refuelling, as is the case for Predator and Global Hawk, the aerostatic robots offer the best performances. Currently the army uses some RAID (Rapid Aerostat Initial Deployment), with a flight autonomy of five days and able to reach an altitude of 1000 feet. This model was used in Afghanistan with decent results. However, much more sophisticated aerostats are being built, such as the JLENS (Joint Land Attack Elevated Netted Sensor), fitted with radar and sensors, able to keep flying at 15 feet for 30 days. Twelve specimens of this model have been planned in 2009. Or the revolutionary PERSIUS of HUAV (Hybrid Unmanned Aircraft Vehicle) typology, manufactured by Lockheed Martin Aeronautics, fitted with sophisticated sensors, capable of flying for three weeks at 20,000 feet without returning to base, and able to move with a hybrid propulsion system.

Other 'flying robots' have shown themselves to be particularly useful to the armed forces because of their small dimension and their easy launch and recovery. In this category we find: small gunships like the Wasp by the AeroVironment, of which almost one thousand specimens have been manufactured; micro-mini aircrafts like the RQ-20 Puma (1137 specimens in service in 2013) or the RQ 11 Raven (7332 specimens in service in 2013); and remote controlled helicopters like the XM 157 Class IV UAS, with 32 specimens provided for the Brigate Combat Team in 2009.

The most futuristic model of robotic aircraft the Roadmap mentions is no doubt the $\mathrm{X} 47 \mathrm{~B}$ by Northrop Grumman Corporation, still at the prototype stage and belonging to the category of Unmanned Combat Aircraft System. Its shape is reminiscent of the interceptor ships of the TV series Battlestar Galactica, and so much so that one might mistake them for an alien spaceship. Only this time the UFO does not contain green men, or men of any other colour. Its captain is the grey matter of the on-board computer. It must be able to take off both from runways and from aircraft carriers, to fly at an altitude of 40,000 feet with 9 hours autonomy, and to carry weapons and bombs of reduced diameter.

Its first ground flight took place took place at Edwards Air Force Base, California, on 4 February 2011. As we read in the Northrop Grumman's website,

[i]n 2013, these aircraft were used to successfully demonstrate the first ever carrierbased launches and recoveries by an autonomous, low-observable relevant unmanned aircraft. The X-47B UCAS is designed to help the Navy explore the future of unmanned carrier aviation. The successful flight test program is setting the stage for the development of a more permanent, carrier-based fleet of unmanned aircraft [20]. 
Italy as well has a tradition of designing and building robotic aircraft. Feletig [12] only mentions the Sky-X and Sky-Y by Alenia, but the Falco, manufactured by SELEX Galileo and designed by Galileo Avionica, certainly also deserves to be mentioned. It is a small size tactical aircraft designed for reconnaissance and surveillance. Its first flight took place in 2003, but the machine has been officially in service since 2009. Even though the SELEX has not rendered public the name of the user, one knows that five systems (a total of 25 aircrafts and corresponding ground control systems) have been sold to Pakistan. In August 2009 the UM Falco was launched using a Robonic MC2555LLR catapult and has completed the test flight. The first flight by aircrafts fitted with high resolution radar and sensors called PicoSAR (synthetic aperture radar) took place in September the same year. In August 2013, the Selex ES Falco was chosen by United Nations to be deployed in the Democratic Republic of Congo "to monitor the movements of armed groups and protect the civilian population more efficiently" [19]. The Falco flies at $216 \mathrm{~km} / \mathrm{h}$ and can reach a height of 6500 meters; it is 5.25 meters long and weights 420 kilograms. It is not designed for combat, but a model called 'Falco Evo' fitted with weapons is currently being studied.

\subsection{Sea Robots}

Unmanned Maritime Systems (UMS) “comprise unmanned maritime vehicles (UMVs), which include both unmanned surface vehicles (USVs) and unmanned undersea vehicles (UUVs), all necessary support components, and the fully integrated sensors and payloads necessary to accomplish the required missions" [46, p. 8].

As regards military robots operating at sea, above or below water, the main mission would seem to be mine hunting. There exists a whole collection of submarines with a shape and propulsion engine similar to those of a torpedo, but fitted with a 'brain' and sensors. The primary task of these machines is the ability to spot mines from among other objects, also taking into account the difficulties specific to marine environments that differ from conditions on land.

Relevant companies are fiercely competing to produce the prototype whose performance will ensure their leadership. Statistics are used to detect the object correctly. Still today it happens that all sorts of objects are mistaken for mines or, worse, that genuine mines are not recognized. We shall not give a lengthy description of the technical features of these machines, but confine ourselves to mention one submarine and one surface vehicle.

Amongst the Unmanned Undersea Vehicles one may take note of the Swordfish (MK 18 Mod 1) by Hydroid LLC, a company that is particularly active in this sector. As for surface vehicles, one example is the MCM (Mine Counter Measures) by Oregon Iron Works, currently in the experimental phase. Surface vehicles for other tasks are also being designed, such as the ASW USV, whose function is revealed by its name: Antisubmarine Warfare Unmanned Surface Vehicle; or the Seafox, an unmanned motorboat specialized in coastal surveillance and patrolling.

\subsection{Land Robots}

Land robots or, more precisely, Unmanned Ground Systems (UGS) "are a powered physical system with (optionally) no human operator aboard the principal platform, which can act remotely to accomplish assigned tasks. UGS may be mobile or stationary, can be smart learning and selfadaptive, and include all associated supporting components such as operator control units (OCU)" [46, p. 6].

The main mission of land military robots is to clear the ground of mines and explosive devices that are a true nightmare for the Allies' soldiers in Iraq and Afghanistan. Because of their widespread use in this field the MTRS (Man Transportable Robotic System) MK1 and MK2, produced by i-Robot Corp. and by Foster-Miller Inc. respectively, should be mentioned. The Roadmap 2009-2034 reports that a good 1439 specimens of these machines are already found on the battlefield, but the goal is to roll out 2338 in the coming years. These very useful machines detect and neutralize the explosive devices that military contingents encounter on their path. On the 
battlefield 324 MK3s by Northrop Grumman Remotec and 1842 MK4s by Innovative Response Technologies are also in use. These are budget robots that save the lives of a great number of people.

While deminers have been widely used for a long time, the same cannot be said of combat robots (the so called TUGV - Tactical Unmanned Ground Vehicle), that is, of machines with no human operator, that are capable of attacking and killing human beings. Various prototypes are currently studied. One of these is Gladiator, of which six specimens have been produced by Carnegie Mellon University for the Marine Corps. Gladiator is an armed and armoured combat robot, endowed with a collection of sensors and weapons that include: infrared sensors, video camera, rocket launcher and machine guns of type M240 and M249. The vehicle moves on wheels, can be remote controlled by a soldier up to one nautical mile away and is equipped with a system that hides the exhaust gas.

Another machine destined for combat is the Armed Robotic Vehicle (ARV) by BAE Systems, and produced by the US Army. 679 of these have been commissioned in 2009. It weighs 9,3 tons and has been designed to perform two specific tasks. The first is reconnaissance: indeed, the ARV-RSTV model (Reconnaissance Surveillance Targeting Vehicle) is able to scan an area and find, detect and reconnoitre targets with great precision, thanks to its sophisticated on-board sensors. Instead, the ARV-A model is fitted with a range of lethal weapons, among which a medium-calibre cannon, a missile launching system and machine guns. Once the experimental stage is completed, it will be possible to use this model in combat.

However, ground warfare has come to a halt. Among the many reasons one can list the misfortune that happened to Forster-Miller's SWORDS. This is a tiny caterpillar robot carrying a light M249 machine gun. The press and the manufacturer give different accounts, but it would seem that the robotic weapon did not behave as it was supposed to.

On April 11 2008 The Register published a gloomy headline: "US war robots in Iraq 'turned guns' on fleshy comrades." The author tells how the robotic vehicle began to behave unpredictably, stopped obeying orders and spread panic among the soldiers. The tone varies from ironic to apocalyptic: "American troops managed to quell the traitorous would-be droid assassins before the inevitable orgy of mechanized slaughter began... the rogue robots may have been suppressed with help from more trustworthy airborne kill machines, or perhaps prototype electropulse zap bombs" [21].

The news was followed above all by Popular Mechanics, which interviewed Kevin Fahey, the US Army program executive officer for ground forces, about this incident. He confirmed it and explained that the robot began to move when it was not supposed to move and did not fire when it was supposed to fire. No human was wounded, but the drill was stopped from precaution. The officer added that "once you've done something that's really bad, it can take 10 or 20 years to try it again" [42].

In reality, in a later article, also published by Popular Mechanics, Fahey explained that the SWORDS war robots are still in Iraq, and that they have been neither destroyed nor withdrawn. Cynthia Black, Foster-Miller's spokesperson, also wished to explain that "the whole thing is an urban legend" [42]. Black clarified that it is not a self-driving vehicle. That it can therefore not fire unless told to do so. That the uncommanded movements were due, not so much to the computer going awry, but to a trivial mechanical problem. The robot was put on a 45-degree hill and left to run for two and a half hours, and the motor overheated. When this happens, the engine automatically switches off to avoid breakage. But because it was on a slope the machine started to skid, and gave the impression of autonomous movement. This is the producers' version. Fact is that three SWORDS war robots have really stayed on the battlefield, but placed in fixed positions. Some senior official even wondered if it would not be more practical to put the machine guns on tripods.

So one is given to understand that a hypothetical slowing down of the experimentations is not due to this trivial incident, but to a much more important structural situation, such as the economic crisis that has plagued the United States for the past years and the contextual withdrawal 
of US troops from Iraq, expected by the end of August 2010 and completed 10 days ahead of schedule.

Experiments continue in Afghanistan and in laboratories. Also under study is an Unmanned Ground Vehicle, able to spot chemical, biological, radiological and nuclear (CBRN) devices. The iRobot is in fact designing this kind of machine for the US Army.

But the robots on the battlefield can also reveal themselves useful, not only for observing the enemy, unearthing and detonating bombs or fighting. They can also massively assist the wounded during belligerent missions. Many times the wounded cannot be recovered or cured, and therefore they die from blood loss or from the wounds they have incurred, because the place where they find themselves is out of reach or under enemy fire. Here is a machine that can carry out this delicate and dangerous task instead of the stretcher-bearers or of machines operated by humans. Applied Perception Inc. has produced a prototype of Robotic Combat Casualty Extraction and Evacuation. In reality, it is a robot couple. A 'marsupial' vehicle serving as ambulance and connected to a vaguely humanoid machine, with mechanical arms, serving as paramedic. The vehicle is endowed with laser, radar, sensor and systems of navigation that permit it to avoid obstacles and to reach the location of the wounded. In addition the machine is endowed with a telemedicine audio-video system that allows the patient to communicate remotely with a doctor.

The press tells us of other innovative projects that might become a reality in the future for military and civil personnel. All the UGVs mentioned in the Roadmap are endowed with wheels, because it does not yet seem that humanoid bipedal models are combat-ready. However, it seems only a matter of time. The performances by the Boston Dynamics 'quadruped' called Big Dog are indeed astounding. In a Fox News footage, Matt Sanchez describes it as follows:

Using a gasoline engine that emits an eerie lawnmower buzz, BigDog has animalinspired articulated legs that absorb shock and recycle kinetic energy from one step to the next. Its robot brain, a sophisticated computer, controls locomotion sensors that adapt rapidly to the environment. The entire control system regulates, steers and navigates ground contact. A laser gyroscope keeps BigDog on his metal paws - even when the robot slips, stumbles or is kicked over. Boston Dynamics says BigDog can run as fast as 4 miles per hour, walk slowly, lie down and climb slopes up to 35 degrees. BigDog's heightened sense can also survey the surrounding terrain and become alert to potential danger. All told, the BigDog bears an uncanny resemblance to a living organic animal and not what it really is: A metal exoskeleton moved by a hydraulic actuation system designed to carry over 300 pounds of equipment over ice, sand and rocky mountainsides [27].

This robotic animal cannot fail to attract the attention of the Italian press. Fabrizio Cappella writes in Neapolis that "it seems midway between a dog and a giant spider: it has four legs, no head and it walks on broken ground across obstacles: it is called Big Dog and its video has set ablaze the imagination of internet surfers who, for some time now, have fired the wildest comments at the bizarre creature" [6]. The article reveals that this is a project funded by the Pentagon, and that its full name is "Most Advanced Quadruped on the Earth."

Effectively, Big Dog's locomotion is surprisingly natural also on very rough terrain, where it manages to keep its balance in the toughest situations, for example after it has been kicked or after having slipped on ice. The robot moves at about $4 \mathrm{mph}$ and its frame is made of steel: hidden inside, in addition to the petrol engine, are a computer, sensors, video cameras and a global positioning system. It is capable to transport hundreds of kilos of gear and can withstand collision with wheeled vehicles and caterpillars. Its purpose is military; one studies its usefulness to troops in warzones, its ability to carry heavy loads and to transport the wounded. The Pentagon appears to have great faith in the success of the project, given that it has invested 10 million dollars in the prototype. Now in its second version, Big Dog will be further developed and its definitive version 
ought even to be able to gallop thanks to the form of its legs that are very similar to those of racing animals.

The comments found online are divided. Some are enthusiastic and others admit to being intimidated and concerned. Here two fundamentally opposed ethical leanings play an important part: on the one hand technophilia (the pride of belonging to the human species, able to build these wonders), on the other technophobia (the refusal to give up pre-industrial or pre-Neolithic lifestyles). What is certain is that this machine, whose locomotion is so similar to that of living beings, does not leave one indifferent.

Another machine that thrills the imagination and stirs up discussion among journalists and readers is a robot called EATR (Energetically Autonomous Tactical Robot), not because of the weapons it carries or because of its locomotive capacities, but because of its system of propulsion and fuel supply. Here it would be appropriate to use the term 'feeding,' which refers as much to machines as to living beings. Effectively the EATR is fuelled much like a human being. Riccardo Meggiato writes in Wired:

Don't be scared if one day, pretty soon, you see a robot among the grazing cows: robots also eat, didn't you know? The EATR, an acronym that does not refer to some exotic train but stands for Energetically Autonomous Tactical Robot, is a model that feeds itself: it literally eats plants and converts them into biofuels that it uses to move. The ultimate purpose of this project, still under development, is to create vehicles that cannot only do without classic fuels, but are also able to provide for their own energetic needs. The EATR is the work of Robotic Technology in Washington, and its development is funded by Defence Advanced Research Projects Agency (aka DARPA). All right, it's the army longing to create autonomous military vehicles, but it is also clear that this kind of technology, once in place, could benefit many different sectors [16].

Wired also reveals some of the technical features of the feeding-propulsion system:

So how does this cool gizmo work? Oh, it's easy: it forages plants with a mechanical limb and ingests them into a combustion chamber. Once on, it generates heat that warms up reels filled with deionized water, which evaporates. The steam obtained then activates the six pistons of a special engine, which activates an energy generator. This one, finally, is stored in specific batteries and used if needed. To give the system more autonomy, researchers at Robot Technology have developed a range of recovery solutions. For example, if steam escapes from the pistons it is promptly condensed, turned into water and sent back to the combustion chamber. And if there is a shortage of grass to graze, no worries: EATR can happily run on traditional fuels as well, like diesel, petrol, kerosene, and even cooking oil. This, cows can't do [16].

So the robotic system promises a solution to one of the major problems that Unmanned Ground Vehicles encounter: poor autonomy. In order to function on the battlefield, sometimes far from provision lines, it is important not to be constrained by matters of energy. An electric battery may be enough for a vacuum cleaner or a lawnmower, but its performance is unlikely to do for a robotic soldier lost in the Afghan mountains.

Robert Finkelstein, the boss of Robot Technology, guarantees that 68 kilos of plants make the EATR energy autonomous for about $160 \mathrm{~km}$. The vegetarian engine has been construed by Cyclone Power Technology from a design by the research centre in Washington. The first experiments predict their integration into a Humvee type military vehicle. Whether it will be massproduced will depend on the test results, but the producers obviously hope to send the EATR to the battle scene as soon as possible.

Hence Meggiato concludes: 
EATR applications are manifold and go beyond the military. While some have ironically pointed out that they can also be used as weapons to gobble up enemy troops, others view them as tractors ready to work non-stop without refuelling, possibly controlled by another robotic system that does not need human intervention. In the end, whether it is a Terminator or a Winnie the Pooh in high tech wrapping, the future will be vegetarian [16].

\section{The Main Functions of the Military Robots}

Robots are given the missions that military jargon defines as dull, dirty, or dangerous. In other words, even if some technologies are still not up to replacing man in every relevant task, it does appear rather obvious that the human element is from now on the limiting factor in carrying out certain war missions.

Hard work. Sometimes the battlefield requires work done that the human organism finds it difficult to endure. For example, a human pilot needs a few hours sleep after a long operation; a drone does not. While the longest manned air missions of operation Enduring Freedom lasted around 40 hours, there are now drones that guard some warzones non-stop, remote-controlled by crews on the ground that change every 4 hours. The only limit is aircraft autonomy, but if refuelling can be done in the air then that limit too is removed.

Dirty work. As the Roadmap 2007-2032 reminds us

[US] Air Force and Navy used unmanned B-17s and F6Fs, respectively, from 1946 to 1948 to fly into nuclear clouds within minutes after bomb detonation to collect radioactive samples, clearly a dirty mission. Unmanned surface drone boats, early USVs, were also sent into the blast zone during Operation Crossroads to obtain early samples of radioactive water after each of the nuclear blasts. In 1948, the Air Force decided the risk to aircrews was 'manageable' and replaced unmanned aircraft with manned f-84s whose pilots wore 60-pounds lead suits. Some of these pilots subsequently died due to being trapped by their lead suits after crashing or to long-term radiation effects [8].

These incidents persuaded the US military to revert to using robots for dirty work.

Dangerous work. Explosive Ordinance Disposal (EOD) is the primary example of dangerous work entrusted to robots. Improvised contrivances found in the streets and in places where soldiers go constitute some of the major threats in the current military campaigns in Iraq and Afghanistan. Coalition forces in Iraq neutralized over 11,100 Improvised Explosive Devices (IED) between 2003 and 2007. A great percentage of these missions was done by ground robots, and the number of UGVs employed in these tasks has skyrocketed: they were 162 in 2004, 1600 in 2005, over 4000 in 2006, 5800 in 2008.

In order that the performances of military robots meet aspirations, commanders on the field at the head of the different armed forces have been asked to submit a priorities list engineers should focus on. Even though the demands of the ground, air and naval armies differ for obvious reasons, it has become clear that they have four common priorities:

1) Surveillance and reconnaissance;

2) Target identification and designation;

3) Counter mine warfare;

4) Chemical, biological, radiological, nuclear explosive (CBRNE) reconnaissance.

Surveillance and reconnaissance. The main priority has revealed itself to be reconnaissance capacity (electronic and visual). For many army professionals information, qualitative and quantitative, is the key element for operational success and robots are the best candidates to gather this information. The ideal robot is able to exert persistent surveillance (or for long periods) on hostile areas, while 
maintaining some degree of 'covertness.' Robots are promises that the limits of other systems such as manned vehicles, satellites, submarines and unattended sensors will be overcome.

Target identification and designation. The ability to identify and to locate targets with precision in real time is one of the most urgent necessities on the battle stage. It is necessary to reduce the 'latency' and to increase the precision for GPS guided weapons, as well as the ability to operate in high-threat environments without putting warfighters at risk. A quality leap in this sector would improve not only safety, but also be more efficient and efficacious than traditional manned systems.

Counter-Mine Warfare. The most useful yet dangerous mission is that of demining a piece of land or sea. Statistically speaking, since World War II, sea mines have caused more losses of US warships than all other weapons systems combined. The same can be said of landmines and bombs (IED - Improvised Explosive Devices) that are responsible for the majority of losses of the coalition forces in Operation Iraqi Freedom. Commanders regard improving the robot's capacity to find, tag and destroy these devices as a priority. Henceforth robots appear irreplaceable for this sort of work. They have already saved innumerable lives and, as their technology improves, this ought to reduce casualties still further.

Chemical, Biological, Radiological, Nuclear, Explosive (CBRNE) Reconnaissance. The dirtiest of dirty work is that of spotting CBRNE. Yet this kind of weapon of mass destruction also represents the greatest peril for a nation at war. An attack with nuclear, chemical or biological weapons on foreign land or on troops deployed at the front, would have disastrous consequences not just on the waging of the war, but also on the entire military apparatus, on the economy and on foreign policy broadly speaking. Therefore robots are essential, as much to prevent this kind of attack as to observe and monitor areas that have already been attacked, because of their superior sensorial capacities and because of their greater resistance to chemical, radioactive and microbial agents.

In the Roadmap 2007-2032 the future goals that constructors and users of robotic weapons in military circles have set themselves are the following:

1) "Improve the effectiveness of COCOM [combatant commander] and coalition unmanned systems through improved integration and Joint Services collaboration" [8]. To this end one expects new designs and experiments on the battlefield with the most promising technologies, accurately testing prototypes prior to their deployment. Reducing the risk in the use of fully developed technologies is also part of the project.

2) "Emphasize commonality to achieve greater interoperability among system controls, communications, data products, and data links on unmanned systems" [8]. Also here the stress is both on security and on safety. On the one hand, it is necessary to improve the 'common control' and 'common interface,' so that the control systems can easily operate the various kinds of robots. On the other hand, it is important to prevent interceptions, interferences, hijacking, so that the enemy cannot take control of these machines and turn their lethal potential against the army owning it.

3) "Foster the development of policies, standards, and procedures that enable safe and timely operations and the effective integration of manned and unmanned systems" [8]. These goals include:

a) developing, adopting and prescribing commercial and government regulations relative to the design, construction and experimentation of unmanned systems;

b) the coordination between the civil authorities that manage the air, sea and land areas for civil usage (the transport of goods and passengers) and the military authorities in order to prevent collisions between manned and unmanned machines;

c) the development of ever better systems of sensors and control, to give robots the necessary autonomy to avoid collisions with traditional means of transportation.

4) "Implement standardized and protected positive control measures for unmanned systems and their associated armament" [8]. More specifically, one feels the necessity for a standard architecture common to all unmanned systems, armed or not. 
5) "Support rapid demonstration and integration of validated combat capabilities in fielded/deployed systems through a more flexible prototyping, test and logistical support process" [8]. More specifically, one intends to develop alternatives to gasoline-powered internal combustion engines, with a particular predilection for high-energy-density power sources (primary and renewable), and if possible common with those of manned systems.

6) "Aggressively control cost by utilizing competition, refining and prioritizing requirements, and increasing interdependencies (networking) among DoD [Department of Defense] systems" [8]. In other words, stimulate both competition among manufacturers and their cooperation, while keeping cost reduction as the primary goal.

New requirements were added to this list, punctually recorded in the updated and integrated Roadmap 2009-2034. In particular, one can see that the army insists less on control procedures and security standards, and more on the speedy production of the machines and on their necessary autonomy. This is an important change, which in our opinion reflects the fact that, in recent years, robots came to be viewed as more reliable. So we add the two key points:

7) To maintain the sectors of research and development to increase the level of automatization of the systems of robotic weapons, so that they reach the appropriate level of autonomy, as determined by the combatant for each specific platform.

8) Speed up the transition of robotic weapons systems from the sectors of research and development set up by scientists to the hands of the combatants at the front.

It is therefore considered opportune to maximally stimulate the production and use of ever more sophisticated military robots, because of the army's ever more enthusiastic reception and implementation of the robots that arrive on the battle stage. Hence moral uncertainties appear to fade away. Besides, operations like demining and the clearance of explosive device in areas either inhabited or in some way traversed by people, as well as the prevention of attack with chemical, biological or nuclear weapons, will hardly raise any ethical objections. What robots do and will go on doing on the field, in time of war and in time of peace, is nothing other than humanitarian work. The same can be said of aid to the wounded. However, it is true that other questions, such as electronic combat and surveillance, could still raise questions of a moral nature. Add to that man's atavistic fear - symbolically codified in myths, legends and tales - of a rebellion by the creatures against their creator, and one understands that robotic technologies promise to become a main area of applied ethics.

\section{Main Objections to the Belligerent Use of Robots}

Given that many look upon war as a negation of ethics (sometimes also when it is defensive), and that technological development itself finds firm adversaries on principle, it is not astonishing that the application of robotics to war has stirred up so much discussion [25], [35], [37], [2], [1], [7], [36], [11], [47].

The question however does not engage just pacifists, Luddites, and roboethicists, but also military professionals and engineers. The development of this kind of operation does indeed promise to solve many problems, but it is not without its pitfalls. The debate is therefore more necessary than ever. Here we shall outline the moral objections to the use of military robotics that we have found most cogent, and, in a second part, we shall evaluate them both from a technical and ethical point of view.

\subsection{Noal Sharkey's Plea}

A plea by the Royal United Services Institute (RUSI) that denounces the dangers of a robotic arms race and the risk that it would imply for all humanity has caused a particular stir in the media. The plea has made headlines because it is written by experts in the new technologies and, moreover, for so prestigious an institution as the RUSI. Those who are informed about military matters know well that the RUSI is not some hangout of pacifists or Luddites. 
This point of view has found one of its more notable spokespersons in Noel Sharkey, professor of Computer Science at the University of Sheffield. According to him,

the trouble is that we can't really put the genie back in the bottle. Once the new weapons are out there, they will be fairly easy to copy. How long is it going to be before the terrorists get on in the act? [...] With the current prices of robot construction falling dramatically and the availability of ready-made components for the amateur market, it wouldn't require a lot of skills to make autonomous robot weapons [39].

The first argument that the anti-robot front puts forward is therefore the possibility that the enemy could use these creatures against us. Strictly speaking, this is a prudential argument rather than an ethical one. Indeed, it is about our own good, rather than the good of other fellow humans. There is a fear that our own drive for hegemony can turn against us. Western nations are apparently investing huge amounts of money in the construction of these war machines (4 billion dollars in 2010 and a total expense of 24 billion dollars in the case of the United States), but once they fall into enemy hands they are easy to copy. At what point will Islamic fundamentalists or other enemies of the West no longer need kamikaze and suicide bombers, but will be able to direct remote controlled drones with lethal charges against preselected targets? Sharkey has been interested in this problem for a long time, and also worked as an advisor to the BBC during the broadcast of the television series Robot Wars.

Maruccia observes that "the professor does not give much detail as to this presumed facility to build, but he does assure us that a drone equipped with an autopilot guided by Sat Nav currently carries the modest price tag of 250 dollars" [15]. He probably refers to mini drones, given that a Predator costs around 4 million dollars, but we can certainly bet that the cost of these technologies will fall substantially. In addition, it is true that mafias and terrorist groups sometimes dispose of large sums of money and that, for the sum that a Nation spends on the purchase of a supersonic jet plane, one can buy 30 Predators.

The second ethical problem that Sharkey brings up is the drones' limited capacity to discern, that is, the possibility of error: because of the 'relative blindness' of the machines currently in use it is not possible to guarantee the discrimination between combatants and innocents or a proportional use of force as required by War legislation:

Allowing them to make decisions about who to kill would fall foul of the fundamental ethical precepts of a just war under jus in bello as enshrined in the Geneva and Hague conventions and the various protocols set up to protect civilians, wounded soldiers, the sick, the mentally ill and captives. There are no visual or sensing systems up to that challenge [30, p. 87].

In an article appeared a few months later on Science, Sharkey clarifies that "even with a definition [of a noncombatant], sensing systems are inadequate for the discrimination challenge, particularly in urban insurgency warfare" [31].

Here the misgiving is mainly ethical, because it concerns others' safety. But let us add that the error could also consist in killing allied soldiers. The so-called friendly fire. Because of this, Sharkey solicits a serious international debate, one which also takes hypotheses of a moratorium into consideration: "With prices falling and technology becoming easier, we may soon see a robot arms race that will be difficult to stop. It is imperative that we create international legislation and a code of ethics for autonomous robots at war before it is too late" [29]. In other words, the international community should evaluate the risks of these novel weapons now, rather than sit around and wait while they sneak their way into common use. 


\subsection{Robotic Wars as War Crimes Without Criminals?}

The question of the possibility of errors is raised also by Andrew Brown in a blog related to The Guardian. However, he lays the stress above all on the matter of relieving oneself from the burden of responsibility. Reflecting on the concept of hostile artificial intelligence, Brown warns that the robot has a particular status that it is hard to define: it is not yet a sentient being capable of moral discernment, but neither is it a mere object controlled by man: it has a goal and it pursues it, even though it does not know that. By the way, this is true also for the so-called smart bombs, that follow heat or satellite signals: "The missile, a thing that is both dead but none the less animated by a hostile purpose, violates some primitive expectations of the way the world works. That's one reason it seems so frightening" [3].

Brown raises the problem of the moral status of the robot, of the people that are constructing it, that give the order to use it, and that use it. He rejects the idea of those he calls "the protagonists of extreme artificial intelligence," for whom the robot is considered on a par with humans once its behaviour becomes indistinguishable from that of a human (that is, that it passes the famous Turing test). He therefore proposes a further ethical problem linked not so much to the blindness as to the possible lunacy of the robotic soldier. He asks

what would happen to a robot which acted against its programmers' intentions: if it started to shoot everyone less than four feet high, or offer sweets to anything armed with an RPG? ${ }^{2}$ The answer is obvious. It would be either reprogrammed or destroyed. A human, on the other hand, would be tried, because a human could be blamed - or praised for what he had done.

According to Brown, an entirely unprecedented problem arises in the presence of hostile artificial intelligence: we could have war crimes without the possibility of identifying for certain the war criminals.

\subsection{Trivialization and Multiplication of Armed Conflicts}

Also Peter W. Singer has dealt with this question in a lengthy and detailed article that appeared in The Wilson Quarterly [32]. Singer begins by describing the death of a soldier, one much appreciated by his fellow soldiers and by his commander for his courage, tenacity and ability. He had saved many lives but, during a demining operation, the device that he was trying to deactivate exploded, killing him. His comrades in arms picked up his remains and carried them away from the scene by helicopter. When writing their report, the commander lavished words of praise and gratitude for the soldier that offered his life, but said that, at least, there was one thing he was relieved about: "When a robot dies, you don't need to write to its mother."

The death of PackBot cost US taxpayers 150,000 dollars. It will be replaced with few tears shed by its clone. Or by a more advanced model.

Singer starts out with this example to argue that robotic war opens up new sociological, psychological, ethical, legal, and political scenarios. A novelty comparable to that offered by World War I, the first major conflict after the industrial revolution. Drawing inspiration from science fiction writers of the time (H. G. Wells, A. A. Milne. Arthur Conan Doyle, Jules Verne, etc.), farsighted politicians like Winston Churchill and engineers tried hard to put previously unseen 'steel monsters' on the battlefield: armed tanks, aeroplanes and submarines. This brought war to a level it had never reached before. The biggest novelty was that the new weapons (machine guns, gas, armoured tanks, etc.) made a carnage of any attempt to move the front just a few meters, while planes and zeppelins managed to bring the war from the front to inhabited cities and unarmed civilians, and submarines came to threaten passenger ships and unarmed freighters. It radically altered the way in which war was fought, and not just as regards the strictly technical, but also the human. 
The same is happening now with robotic arms. Singer, even though he underlines the obvious positive aspects of these weapons for whoever has them, that is, that they spare human lives in one's own faction, he brings up another question for ethical discussion, that someone has called 'the videogame effect.' Those who fight with robotic means are very far from the battlefield and do not always feel as if they were killing living and sentient beings. We could refer to this problem with an expression: 'trivialization of war.'

The testimonies that Singer collects give a fairly clear idea of the new psychological dimension the fighter finds himself in. While the Predator's sensors spot the enemy on the mountains of Afghanistan and attack him with lethal weapons, the human pilot is 7500 miles away in a military base in Nevada. The experience is that of a psychological disconnection between being 'at war' and leading a normal working life. A pilot of Predator describes the sensation as follows: "You see Americans killed in front of your eyes and then have to go to a PTA [Parent Teacher Association] meeting." Says another: "You are going to war for 12 hours, shooting weapons at targets, directing kills on enemy combatants, and then you get in the car, drive home, and within 20 minutes you are sitting at the dinner table talking to your kids about their homework" [32].

Another interesting question that Singer raises concerns control, human presence in decision-making. This is the EURON Codex's first point: "Safety. We should provide for systems for the control of robots' autonomy. Operators should be able to limit robots' autonomy when the correct robot's behaviour is not guaranteed" [40, p. 617]. Or, to say it like Eliot Cohen - an expert on military questions who has worked in the State Department under the administration of George W. Bush - "people will always want a human in the loop." Although we may want this, it is time to ask if this is technically possible, if it will not lead to rather paradoxical situations.

In fact, as the number and quality of robotic arms improve, humans will get expelled from the 'loop' little by little. This process was visible already at the time when electronic weapons emerged (radar, radio, sonar, etc.) in the first half of the 20th century [1], and is becoming ever more visible today. Let's begin with an example. During the Gulf War, the captain and radar navigator Doug Fries describes bombing operations as follows: "The navigation computer has opened the aircraft hold door and unhooked the bombs into the dark." Of course other human beings programmed the machines initially, but then one allowed the computer to take over on the battlefield, giving the pilots a merely auxiliary role.

The most tragic event in connection with this kind of procedure took place also in the Persian Gulf in 1988: the case of Iran Air Flight 655. In the eighties US naval ships had been endowed with the computerized defence system Aegis that had four different modalities of action. Among these were the 'semi-automatic' modality, which gave humans the possibility to decide if and what to fire at, and the 'casualty' modality designed to run the ship and defend it if all the men on board were dead. On July 3rd 1988, the USS Vincennes, renamed Robo-cruiser for the Aegis system and because of the captain's aggressive reputation, detected the presence of an aircraft and identified it as an Iranian F-14, and therefore signalled it as an 'assumed enemy.' Although Aegis was set in 'semi-automatic' mode, that is, with the machine given minimum decisional autonomy, none of the eighteen marines and officers of the command wanted to take the responsibility of contradicting the computer. Hence they followed its advice and authorized fire. The missile destroyed an innocent passenger plane with 290 passengers on board, among which 66 were children.

Let us therefore make a list of the errors made:

a) The Aegis is designed to oppose the action of Soviet bombers in the north Atlantic in war time and acted according to these directives, and yet it found itself beneath a sky full of civilian planes in peace time;

b) His great trust in computers lead the commander to drop a security procedure that envisaged asking higher officials on other war ships for permission;

c) once again, deep faith in computer wisdom induced the captain and his collaborators to blindly listen to the advice of the machine, despite the improbable nature of an Iranian attack. 
Similar errors have occurred with other robotic or automatic weapon systems. During 2003 the invasion of Iraq, a battalion of Patriot missiles took down two allied aircrafts upon having mistakenly classified them as 'Iraqi rockets.'

Here then is what the situation looks like, beyond the problems. In theory, humans are still in the loop, part of the decision-making, but the truth is that decisions have to be made in seconds, between the computer signal and the possibility of one's own death, and therefore no one feels up to using what now boils down to a 'veto power.' One always allows the robotic weapon to fire and hopes that it will strike the enemy and not unarmed civilians or allies. When acting under such psychological stress, it is as if humans had no role to play.

This situation is summed up in what we could name the 'paradox of controlled autonomy.' Many have become aware of the problem, among these the psychologist and expert on artificial intelligence Robert Epstein:

The irony is that the military will want it [a robot] to be able to learn, react, et cetera, in order for it to do its mission well. But they won't want it to be too creative, just like with soldiers. But once you reach a space where it is really capable, how do you limit them? To be honest, I don't think we can [33].

In other words, one first constructs a machine able to do things humans cannot, and then one still expects that humans would have the last word about what the machine ought to do. This is paradoxical.

The result is that, when releasing thousands of robots on the battlefield, one continuously feels the need to introduce exceptions to the general rule that wants humans to have the last say in all decisions. Let us look at it in more detail, reasoning in terms of degrees of autonomy, and not just in a digital one/zero perspective.

First exception. Just as an official has authority over a certain number of human soldiers, one imagines that an operator could supervise a certain number of robotic soldiers. The problem is that the number of robots that a human being can control is directly proportional to the individual robot's degree of autonomy. To understand the problem, let us imagine that we are playing five videogames at the same time. A Pentagon report stresses that "even if the gunship commander is aware of the position of all his units, combat is something so fluid and rapid that it is very hard to control." In other words, if we really want them to fight, and if we cannot assign one commander to every robot, we have to give them the possibility to respond autonomously to enemy fire.

Second exception. No reminder is necessary that the enemy is as sentient and uses electronic arms just as much as we do. As early as the Tsushima battle of 1905, Russians and Japanese used radio waves to spot their mutual presence or to interfere with the communication between battleships [10, pp. 66-74]. If the robotic soldier cannot fire unless a remote operator (a human soldier) authorizes it, then it will be enough to obstruct the communication to render the machines harmless and leave them at the mercy of the enemy. In other words, it makes sense then to set up a plan B in the case communications are cut off which envisages the possibility of robot decisional autonomy. In this case they will be able on their own to defend themselves against threats, hit the enemy and return to the base. We can only hope that they make no mistake.

Third exception. Even if every robotic weapon has its own operator, even if the communication is not broken, even if the enemy does not operate at digital speed, there are situations in combat in which humans cannot react fast enough to neutralize a threat. If a projectile is fired at a robot, it takes a human some time to notice (due to the time of propagation of sound waves, to brain reaction time, to momentary inhibition provoked by noise or fear, etc.), while a robot is at once able to spot the conflagration source and frame it as the target of a laser ray. If one can point a laser at someone who fires, then in the same way one can fire a lethal projectile. That is, if one is working in auto-mode, without waiting for a human operator to give the green light, then one could shoot down anyone firing before he had the time to put away his weapon and hide or run away. It is a very strong argument that soldiers on the field are quick to point out. Which human 
being would risk life and limb, with a very high probability of instant death, in order to kill a machine? Giving the robot enough autonomy to return the fire would totally change war and guerrilla warfare. It would make armed insurgence pointless, because this one is linked to a need for revenge on the occupying forces. Among other things, introducing this exception could seem attractive not just to soldiers, but also to public opinion, which looks rather favourably at the asymmetry between attacking and responding to an attack (even in a 'superhuman' way). The robots do not aggress humans, but eliminates them if they become aggressive and dangerous.

One is also considering the hypothesis of taking exception to the general rule of control, in partial terms, that is, enabling the robot to fire, but only in order to strike machines and not human beings (other robots, armoured tanks, jeeps, etc.). In this case, a robot could block the enemy by targeting wheels or caterpillars. However, in so doing, the robot would not shelter from enemy fire, given that the human operators would or should survive. And it would not shelter fellow soldiers, given that survivors would keep their ability to fire and kill. The dilemma does therefore not go away, and the idea generally speaking of an exception remains a sensible one.

The problem is that, by multiplying exceptions, one risks giving full freedom to the machines. As robotic weapons become more and more reliable, commit fewer and fewer errors, they will get to so high a degree of reliability and, in combination with the technical impossibility for man to replace the machine, we will reach a point of no return. Let us not forget that, indeed, humans too make mistakes. Military history is rich with episodes of friendly fire being more homicidal than enemy fire. Humans are not less dangerous than computers or robots. Even in the presence of errors, it will be enough that statistics weigh the balance in favour of the computer or the robot, to completely remove humans from both battlefield and decision-making.

What might happen in the future, starting with these observations and looking at the technological trends, it is the emergence of yet another ethical problem: the increase of belligerent conflicts. This at least is the opinion of Lawrence J. Korb, an ex marine officer, the author of some twenty books, who has served also as assisting secretary of defence during the Reagan administration. Korb is a great supporter of robotic weapon systems because these save human lives. However, he is persuaded that this is precisely why technological development will make it ever easier psychologically to decide to go to war. There are two factors that push in this direction, and both are the effect of the automation of the armed forces: a) The growing disconnection between the military apparatus and civil society; b) The perverse voyeurism to which emerging technologies give rise.

As Singer reminds us,

Immanuel Kant's Perpetual Peace (1795) first expressed the idea that democracies are superior to all other forms of government because they are inherently more peaceful and less aggressive. This 'democratic peace' argument (cited by presidents across the partisan spectrum from Bill Clinton to George W. Bush) is founded on the belief that democracies have a built-in connection between their foreign policy and domestic politics that other systems of government lack. When the people share a voice in any decision, including whether to go to war, they are supposed to choose more wisely than an unchecked king or potentate" [32].

In other words, since we know that war can bring both victory and glory, or death and despair, and since it directly affects citizens and all their loved ones, democracies strongly pressurize their leaders and urge them to caution and to responsibility rather than to irresponsible adventures. Indeed, glory is mostly to the benefit of the leader, while the loss of loved ones befalls the ordinary citizen. Not forgetting that, in past wars, citizens who had stayed at home, even if they had no friends or relatives at the front, had to face rationing of certain products of consumption (food, clothing, gas) or pay a war tax to sustain the war effort.

But what happens if one sends mercenaries and robots to war instead of citizens, and that one has to put up with neither taxes nor rationing? There will be a general disinterest in the war. 
One is reminded of it only an instant at the airport when one's toothpaste is confiscated because it exceeds the $100 \mathrm{ml}$ limit. In any case, the influence of public opinion in democratic nations is more theoretical than a reality. The United States of America have fought on many fronts in the last half century, from Korea to Vietnam, from the Persian Gulf to Yugoslavia, from Afghanistan to Iraq, not counting all the minor interventions in Latin American nations. However, the last formal declaration of war goes back to 1941. Italy as well has circumvented the constitutional obstacle that only allows for defensive war and classified foreign interventions (the Gulf War, the attack on Yugoslavia, the invasions of Afghanistan and of Iraq, the intervention in Lebanon, etc.) as 'international police operations' or as 'humanitarian interventions.'

The argument put forward by Korb, Singer, and other experts in robotic weaponry is therefore the following: if $21^{\text {st }}$ century wars no longer require the approval of Congress, if there is no rationing, if no special taxes are imposed, and last but not least machines are made to fight instead of humans, then political leaders will be ever more at liberty and have ever better reasons to opt for military interventions.

To give just one example, faced with the massacres in some of the African nations that we have recently observed (think of the ethnic cleansing done in Rwanda, with children and grown ups actually beaten to death with machetes), Western nations have felt impotent. It could have been politically risky to send troops (perhaps via conscription) into such tough conditions, even with the good intention to save children and innocents. Massive losses would lead to electoral defeat of those politicians taking that decision. But if we had the 'robotic weapons of the future,' the decision might have been another. Predators and Reapers, controlled from Nevada or a European base, could have massacred the Rwandese irregular military bands, and saved the lives of many unarmed civilians, without jeopardising the lives of compatriot soldiers. Therefore this is an attractive argument that it will be ever harder to resist, both for the government and for public opinion.

The second issue Korb raises is that of technological voyeurism. Today Predators see the enemy and kills it. They do exactly what humans used to do at the front. The difference is that human soldiers stored these cruel images inside their brains, that is, in hardware that does not allow file sharing (for the moment being at least). They could tell of what they had seen in their war diaries, or on the radio, or on television. But no one else could see it like they had. Today thousands of movie clips made by drones end online, especially on Youtube, visible, downloadable and distributable by anyone. The military calls these video clips 'war porn' because they show all the cruelty of war with no censorship. People - also because in fiction films they are constantly exposed to violence and phenomena such as spurting blood and exploding brains - are not particularly impressed with death on live. As an example, Singer refers to a video in which a Predator strikes a group of insurgents, having their bodies bounce into the air, while one hears the tune of a pop song by Sugar Ray with the title "I Just Want To Fly." This way war is almost transformed into a sport event, a show, in which the audience is ethically numb, cruel, hungry for revenge, and wants entertainment, and feels none of the compassion that one would expect.

This also happens because the US authorities filter the images and only let through those that serve propaganda. The images that show American soldiers hit, mutilated or killed by the enemy are censored. It would be hard to watch a friend, a son or just someone one knows bounce in the air and pass from website to website, in order to satisfy this kind of pornographic voyeurism. Relatives or friends would have the clip removed. Besides, psychologically, it could have all kinds of effects and unpredictable responses: on the one hand it could increase the desire for revenge, on the other hand it might convince public opinion that war is a pointless bloodshed (that of friends or of the enemy).

War reduced to a videogame, with appropriate filters, could act favourably on public opinion and the ruling classes. Thus, paradoxically, the development of robotic weapons, through decreasing the cost of war in human lives and stress, could in the future increase the number of conflicts as whole, and so increase the level of existential risk for all humanity.

But this is not the only ethical problem. In Singer's words, "such wars without costs could even undermine the morality of 'good' wars" [32]. A nation's decision to enter war, in order to 
assist another country that has been aggressed and is close to succumbing, is a moral act especially because that nation is not directly threatened. The moral act lies in the disinterested risk that it takes to lose lives and money. The moral act lies in the collective choice and in the price paid. But if both choice and losses vanished, where is the moral act?

Even if the nation sending in robots in a just war, such as stopping genocide, war without risk or sacrifice becomes merely an act of somewhat selfish charity [...] The only message of a 'moral character' a nation transmits is that it alone gets the right to stop bad things, but only at the time and place of its choosing, and most important, only if the costs are low enough [32].

\section{Analyses and Propositions}

We have included enough arguments of the ethical kind, for or against the use of robotic weapons. We shall now examine them in the light of the principles and the ethical codes that have been elaborated by roboethicists in recent years [41], [13], [4], [38] and in particular the already mentioned EURON Roboethics Roadmap [40].

\subsection{The Impracticability of the Moratorium}

One has, first of all, proposed to bring the robotic arms race to a halt via a moratorium or a ban. Professor Noel Sharkey has formulated the question in precautionary terms, saying in essence that we should hesitate to produce these weapons because they might fall into enemy hands. But this assumes, as its starting point, that only the West is implicated in the manufacturing of these weapons and that hence it is enough to address the editors of the Roadmap and a few others to forestall the peril. In reality many nations have for decades been working on robotic weapons systems. As we have seen, drones have already been used, in the 1940s, by the Americans and in the Yom Kippur War by the Israelites, and in addition the Hezbollah in Lebanon and the Pakistanis also have them. It is hard to believe that the Russians and the Chinese have renounced them. It is necessary to understand that there is more than one player and, consequently, no matter how sensible the arguments of the robo-sceptics are, we find ourselves in a classical strategic dilemma, which makes it impossible to make a just choice, for structural reasons that are independent of any single will.

The model is in fact similar to the so-called 'prisoner's dilemma,' an indispensable casestudy in every textbook of practical ethics, as well as the basic problem in game theory, which demonstrates how two people (or parties, armies, nations, etc.) might not cooperate, even when cooperation would be in the interest of both. ${ }^{3}$ One example of the prisoner's dilemma is the following. Two criminals are arrested by the police. The police does not have sufficient evidence to incriminate them, so it separates the prisoners and visits both of them and gives them the same deal: if the one witnesses in favour of the incrimination of the other (that is, if he defects) and the other remains silent (that is, cooperates), then the accuser is freed and the silent accomplice gets ten years. If both remain silent, both prisoners get just six months in jail for a minor offence. If both betray the other, each is condemned to five years incarceration. Each prisoner must choose whether to betray her/his accomplice or keep quiet. Each is assured that the other prisoner will not be informed that (s)he has been betrayed before the end of the investigation. How should the prisoners act?

Various philosophers and mathematicians have tackled this problem, among whom John Nash, who formulated a solution known as 'Nash's Equilibrium.' One generally agrees on the most likely result of the negotiation. If one assumes that all each player wants is to minimize his own time in jail, it follows that the prisoner's dilemma does not form a zero-sum game, in which each player can either cooperate with the other player, or betray her/him. The only equilibrium in this game is a so-called 'Pareto suboptimal' solution, in which the rational choice induces the two 
players to defect, and get five years, even if the gain for each player would be superior if they cooperated (for just six months).

This dilemma had much success, partially because it was formulated during the Cold War and appeared as a perfect description of the arms race between the USA and the USSR (the two prisoners). It was in the interest of both to stop the race, but mutual lack of confidence impeded cooperation. Nothing has changed much with the robotic arms race, with the difference that now the prisoners are not just two, but many. This renders the solution to the problem at the mathematical level even more complicated.

This is not to say that it would be naïve or useless to state the problem, but simply that it would be naïve to believe that there is an easy solution for it, or that the ethical problem is just a dilemma with a binary choice. To think that one can stop the robotic arms race with a proclamation is like imagining that shouting: "Crimes must cease!" on the rooftops will defeat crime. Crimes can be defeated only if one removes the causes that generate them and at the same time makes sure that the victims and the suspected criminals are not denied their rights. The same goes for robotic weapons. As long as there are wars, nations involved will always want to have the most powerful and sophisticated weapons. So, if these frighten, then one needs to envisage creating a balance of geopolitical forces that makes resorting to war rare and inconvenient. Crying wolf is not enough. We need (and this is a lot harder) to find the lair and tame it.

If convincing a nation to renounce making robotic weapons may seem all but impossible (the reply will be: "Go convince Russia and China, and then we'll talk about it"), the idea however of opening up a debate to regulate its use, also in wartime, is not futile. The same goes for chemical, bacteriological and nuclear weapons. To conclude, one may accept the idea of not using them, but not the idea of not having them.

The goal of 'owning with inhibited use' is perfectly in line with the principles of rational ethics. And it is also compatible with Immanuel Kant's approach to ethics, as well as with some of the principles of ancient traditional morality - Eastern and Western. Effectively Kant's meta-norm known as the 'categorical imperative' can be formulated as follows: "Act in such a way that the maxim of your (subjective) action could become a universal (objective) law." In spirit, if not in letter, it comes close to the principle of reciprocity of Confucian tradition (embedded also in the Gospels): "Do not do to others what you would not want done to you." Applying the categorical imperative (or the principle of reciprocity) to one's own actions, anyone can see if these are moral or not. Thus one could ask a thief: "Would you want burglary to become a universal law, that is, that everybody would steal instead of doing honest work?" It is obvious that rationally the thief would have to give a negative reply, because if everybody stole there would be nothing to steal. If rendered universal, the immoral act becomes impossible.

Of course in war the principle of reciprocity has been often violated. In addition, also at the theoretical level, everybody does not accept the idea that ethics must have a rational foundation or be founded on an egalitarian principle such as the one just outlined. Those who view themselves as 'the elect people' or 'a superior race' or 'a nation with a manifest destiny' could give themselves rights and prerogatives that they do not concede to others. But what we want to stress here is that, contrary to what one might think, an egalitarian approach to ethics does not at all rule out belligerent action. The categorical imperative is meaningful also in the context of war and is compatible also with military operations. We will give just one example. We can kill our enemies in a gunfight, with conventional weapons, also because we have accepted the possibility of dying in such a context. However at the same time we can refuse to pluck out our enemies' eyes, because we would never want this to become a universal law and that our own eyes were plucked out, should we become prisoners. In the end, the purpose of a rational approach to ethics is that of creating conventions and rules that are widely shared, also in situations of lethal conflict. And history demonstrates that this is not a chimerical approach. Even during World War II, which, by virtue of its use of devastating weapons and the total number of casualties, has been the most bloodthirsty conflict in human history, none of the fighting powers - however radical the ideological 
confrontation - violated certain conventions and rules that had been agreed upon: for instance the prohibition to use nerve gas on the battlefield.

To sum up, because of the prisoner's dilemma, it makes little sense to require that nations forgo robotic weapons, especially now that we find ourselves in a phase of history with many and widespread conflicts, but that because of Kant's principle of the categorical imperative, as shown by various historical cases, it becomes possible (and also cautious) to arrive at an international convention that regulates the use of these weapons.

\subsection{Pragmatism As a Remedy for Undesired Effects}

The second major issue Sharkey, Brown, Singer and many others raise has to do with robot errors, to their hypothetical going awry, to the problem of defining the responsibility in the case of slaughter of innocents (as in the emblematic case of the Iranian Airbus in 1988). This is a serious problem with no easy solution, which has occupied both commissions and magistrates. If it is not possible to punish the robot, then it is clear that the responsibilities can be shared (according to the case) among designers, makers and users, as happens with other technological objects.

However let us make one thing clear: the hypothetical elimination of electronic equipment and automatic systems from airplanes, warships and battle tanks does not at all shelter us from possible errors. Human beings are also prone to errors and, worse, deliberate cruelty. When one repeats like a mantra that "the control must remain in human hands," in order to reassure public opinion, this one should ask itself which human hands will indeed control the weapons. Robots may kill civilians by mistake, which indeed is awful, but let us not forget that humans have systematically and deliberately killed civilians out of revenge or cruelty. Think only of indiscriminate bombing of cities in order to sap enemy resistance.

The robot soldier might mistakenly point his weapon at a civilian or kill an enemy that has already surrendered, but the human soldier is capable of worse. He has tortured prisoners, humiliated, mutilated and killed them for the sheer pleasure of it. We can mention the Turks who impaled prisoners, or the Phoenicians who during the Third Punic war mutilated Romans on the walls of Carthage and threw their remains into the air. Or had them crushed by elephants or by the keels of their ships. But without going back this far, it is enough to think of the tortures some US soldiers inflicted on Iraqi prisoners.

Finally, it may be fruitful to discuss the possibility that robots change (blindly) into potential assassins, but we do not think that these problems could be resolved by simply handing control over to humans. Humans are not angels. They could commit atrocities that are much worse than machine errors. Add to this the fact that technology keeps improving, while humans evolve much more slowly, and the argument from error might be overcome in a couple of decades. In other words, one should not think of control as the negation of all autonomy, but rather as the capacity to stop the machine from functioning should the situation degenerate dramatically.

To put it in even clearer terms, the ethical and cautionary problem, once one has adopted a pragmatic perspective, is not resolved by imposing human control as a matter of principle, but by continuous assessment (and so the old procedure of trial and error), which is the procedure that would offer the best results, that is, to achieve our ends with the fewest casualties, both friendly and enemy. This goal can be obtained with human control, with machine control, or with mixed control. Only experience, and statistics, will tell.

\subsection{Voyeurism As an Antidote to Conflict Escalation}

Let us now take a look at the other issues Singer raises relative to the undesirable effects of robotic war: the trivialization of combat, the probable increase of conflicts, a sick voyeurism of our information society, weakening democracies, a growing gap between civilian society and the military apparatus. These issues are all connected and they are not illusory. Were we certain that political leaders of the future would use robotic arms to halt situations of gross injustice, violence, 
human rights violations, we would have nothing to fear. When armed militia or the regular army oppress unarmed civilians, children, minorities, then it is likely that intervening political leaders would have the support of public opinion. However, history tells us that political leaders have started wars for much less noble reasons, such as distracting public opinion from internal political problems, or to favour the conquest of new markets on behalf of the economic and financial lobbies that support them - with fake casus belli constructed using mass media controlled by those same lobbies. If one considers that the lack of morality (understood as acting in one's own interest with no respect for others' life and freedom) can nestle also inside the political and economical classes, the alarm - called by the military and civilians interviewed by Singer - seems more understandable. I would worry more about these aspects of the decision process than about the 'weak morality' inherent in a costless military intervention.

As regards the 'porn war,' I think that there is nothing new under the sun. The medium changes (and this is not without its importance), but surely one cannot blame this phenomenon on computers and robots. Think only about Roman gladiators, about the propaganda spread by belligerent nations during the two world wars, and during the cold war, to portray the enemies as inhuman beings who deserve no mercy and one's own weapons as invincible. Of course there are some new psychological elements, but once again we should take a look at human nature rather than trying to solve the problem by banning Predators or footage online.

The porn war that is all the rage on YouTube satisfies a desire for revenge that is inherently human and atavistic. As for the war in the Middle East, it has been fuelled also by insurgents slitting the throat of American prisoners; these have then been picked up and spread online. In other words, the new media have not at all created these instincts from scratch, but they make them visible. It should also be stressed that, while one part of users seem insensitive or even thrilled by looking at such scenes of violence, there have also been reactions of indignation. Therefore these clips - precisely because of their cruel and violent nature - could have also a positive function, because they show public opinion what war really is. By sensitising public opinion, 'war porn' could induce it to take a greater interest in government decisions, and act as a counterweight to the tendency of military interventions to escalate.

\subsection{Correct Information As a Counterweight to Alarmism}

The new robot prototypes under study, especially those who 'feed' on biomass - the EATR model have also unleashed ethical discussions. On Fox the news were given an alarmist title: "The Pentagon is working on war robots that feed on dead bodies" [24]. This is false. With famous concern, Robot Technology Inc. and Cyclone - the two companies involved in the project immediately denied this statement, and clarified that theirs is a vegetarian robot. But despite the clarification the press insisted. In fact, Italian press agency AdnKronos reissued both theses, and this with a hyperbolic title: "Here comes EATR, the war robot that can feed on flesh: the debate on cyberethics heats up." The agency's first bulletin is telegraphic:

Miami - (IGN) - On the battlefield fallen fighters' dead bodies could be the easiest fuel to use for this new robotic weapon that, in order to work, uses biomass. The manufacturing companies deny this: it is 'vegetarian.' But the discussion on the limits to set on these machines, that scientists foresee will soon be able to make autonomous choices, in order to avoid ethical conflicts has been going on for some time [49]

Later a more detailed revision, but alarming nonetheless, was published on the agency's website: "Miami, Aug. 21 , (IGN) - The robots to which we are used today are at best copying dogs or act as vacuum cleaners that run about the house looking for tiny scraps. But, ever faster, 'mechanical creatures' tackle complex tasks, perhaps on the battle stage, as is happening in Iraq and Afghanistan. The latest robot soldier to arrive on the scene, a transport vehicle that moves fuelled by a biomass engine, that is, it burns organic stuff to run, generates some hesitation in the 
cybernetic world. Indeed, on the battlefield the most common fuel available might well be human flesh" [49].

The problem of robots eating human flesh is on the desk, even though it is now spoken of as a merely academic hypothesis. After all, it is true that there are dead bodies on the battlefield and it is true that the robots feed on biomass, and since dead bodies are biomass, if one plus one equals two... the rest is consequence.

But perhaps this idea arose in someone's head because of its name? "It is called EATR which in English sounds uncannily like 'eater'." And yet the makers cannot be clearer. Harry Shoell, manager at Cyclone, puts it thus: "We completely understand the public's concern about futuristic robots feeding on the human population, but that is not our mission," and he adds that no one would dream of violating article 15 of the "Geneva convention" that prohibits the desecration of the corpses of the fallen. The reporter has to take note of this: "The engine developed to power the EATR runs on fuel no scarier than twigs, grass clippings and wood chips" [49].

Yet, can one easily disregard so gluttonous a piece of news? The humanoid cannibal makes splashier headlines than a lawnmower that recycles greens, so it is better to stress the academic hypothesis:

What would happen, critics ask, if it malfunctioned or ran out of fuel? It would make do with whatever it found, is the answer, and conceive of worrying scenarios along the lines of 'Terminator' or 'Matrix,' science fiction movies where machines take over the planet and use humans as a source of energy [49].

Even though the news is really farfetched, the reporter is right to raise the ethical problem: "In cybernetics the problem of what ethical boundaries should be imposed on these mechanical creations does not go away, given that scientists foresee that very soon it will be possible to make robots able to make largely autonomous decisions." And he cannot avoid quoting Asimov's Three Laws:

The science fiction writer Isaac Asimov, the author of $I$, robot, had for this purpose conceived three simple laws which, in a remote future, would be programmed into the electronic brains of the automatons. The first of the three, fundamental this one, states: 'A robot may not injure a human being or, through inaction, allow a human being to come to harm.' But he certainly had not taken into consideration the problem of a robot which, in order to exist, might be forced to eat human flesh [49].

Once again, we are not so worried about the actual performance of the machine or the use that one will make of it (it has not yet been used), but the fact that it violates a certain idea of how the world works, to put it like Brown. Ordinary people are convinced that there is a neat, ontological, separation between the animal reign and the vegetal reign, the organic and the inorganic, the living and the dead, the conscious and the unconscious. Robots and GMOs demonstrate that these distinctions are just a convenient heuristic model to classify objects, while reality is much more complex and plastic. A robot can draw energy from his environment and feed himself no more no less like a human being or an animal. With the addition that if there be no potatoes or carrots it can also run on gas or petrol. This worries people because it appears to cast into doubt the uniqueness of humans.

Moreover, the mere existence of EATR conveys that it is at least technically possible to build a robot that kills humans and feeds on their flesh, so that it could run for an undetermined length of time. To stop it one would have to switch it off (put it to sleep) or destroy it. If there is no such model it is only because Robotic Technology decided to make it vegetarian. Human creative power fascinates some people and frightens others. Hence the ethical controversy. From a pragmatic and rational point of view, it is advisable to serenely accept the 'fact' that the boundaries between organic and inorganic are transient, and strive for these machines to generate more 
happiness than unhappiness in the world. Taking it for granted that they don't have feelings (happiness or despair), it would be suitable to give priority to humans and therefore give them the authority to stop the machines at any time in case of malfunctioning or unforeseen and negative collateral effects. However, it seems rational to try also to take advantage of it for civilian or military use. After all, EATR is the ideal lawnmower both as to performance and to save energy. And it would be the only robot able to hinder the action of enemy soldiers or militia over many days in a hostile environment, far from the bases and cut off the system of logistic assistance.

\section{Scenario Analysis: Dreams and Nightmares}

What will happen tomorrow? If humans rationally tended to choose what is 'good' and to reject what is 'bad,' for themselves and for others, in theory we ought to see a constant improvement of the human condition. But this can only happen in utopias. The problem is that human choices are not always free. They are not always rational. What is good to one group is not always good for another. What is rational at the micro level (individual, social group) is not always rational at the macro level (society, humanity), and vice versa. And finally there is always the possibility of the 'unanticipated consequences of purposive actions,' already studied in detail by sociologist Robert K. Merton [17]. That is, even if we assume social actors to be rational and have positive intentions, there can always be undesired collateral effects. As a popular saying goes: "The road to hell is paved with good intentions."

For the time being, the development of robotics appears unstoppable. We keep hearing that the $21^{\text {st }}$ century will be the century of robots. This happens because, on the whole, such a development appears 'good,' despite the above-mentioned worries and concerns. It appears 'good' also because the classical idea of virtue as a capacity (courage, knowledge, rationality, selfdiscipline, ability) is once more in favour, and there is no doubt that robots are 'good' in this specific sense. And their 'parents' are every bit as good, since they have been able to transmit to the robots the capacity do to many things. Among these, the ability to fight.

The reason why military applications are being continuously developed is precisely this one: they are 'good soldiers.' First of all they save lives. At the same time they do not have the typically human phobias and weaknesses. In the words of Gordon Johnson of the Pentagon's Joint Forces Command: "They don't get hungry. They are not afraid. They don't care if the guy next to them has just been shot. Will they do a better job than humans? Yes" [43]. Add to this that robots, unlike humans, can be trained and can transmit abilities from the one to the other in an extremely short time: download time. This too is a crucial feature, not just for war, but also in the ever more stringent economical conditions.

At the time of the invasion of Iraq, in 2003, only a handful of drones were in use by the V Corps, the primary command force of the US army. "Today - Singer writes five years later - there are more than 5,300 drones in the US military's total inventory and not a mission happens without them." Therefore, moving on to predictions, one lieutenant of the US Air Force states that "given the growth trends, it is not unreasonable to postulate future conflicts involving tens of thousands" [43].

Between 2002 and 2008, the US defence budget grew 74\% to reach 515 billion dollars, not counting some hundred billion dollars, spent on the interventions in Afghanistan and Iraq. Within this expense, the investment into making land unmanned systems is to double every year as of 2001. The Pentagon's order to the constructors is unambiguous: "Make them as fast as possible."

Singer again compares the current situation with that of the industrial take-off, shortly before World War I. In 1908239 T-Ford cars were sold. Ten years later over a million had been sold. We add that similar situations have been observed with the radio, televisions, computers and telephones. When the home robot boom will take place it will be no less sudden than the technological booms preceding it. The presence of these intelligent machines in homes and in the street will astonish at first, and then be taken for granted. 
As regards war machines, one has reached a limit in the development of some manned systems, in particular as regards supersonic aircraft. For example, the intercepting fighter F 16 is too good, in the sense that it is a lot better than the human pilots flying it. It can operate at high speed and follow trajectories, which to a human pilot would be beyond the physically and sensorially endurable. Only a properly programmed computer could maximally exploit the mechanical and aerodynamic features of the latest generation supersonic fighters.

This also goes for other weapons systems. If land robots were able to respond to gunfire, by means of laser sensors and pointers to identify the target, we would see extremely quick responses. Assuming that, in the future, armies on the field will also include robotic soldiers, with the gradual shortening of the loop, then it becomes clear that presence of humans will no longer be possible on the battle field: our reaction times are far too slow.

Therefore humans must inevitably be replaced by robots if the possibilities offered by engineering are to be fully exploited. Bluntly, in the words of one DARPA official, we will have to take into account that "the human being is about to become the weak link in the defence system."

This is why the US are getting ready to set up a "Future Combat System" (FCS), at a total cost of 230 billion dollars, that Robert Finkelstein describes as "the largest weapons procurement in history... at least in this part of the galaxy" [33, p. 114]. The basic idea is to replace tens of thousands of war vehicles with new integrated systems, manned and unmanned, and to write a 34 million lines long software program for a network of computers that will connect all the war machines on land and in the air. Each individual brigade will have more land robots on the field than traditional vehicles, with a ratio of 330 to 300 , and one hundred drones under the direct control of ground vehicles. The new robotized brigades could be ready for action in the near future.

Future drones will not necessarily resemble Predator or Reaper. We have already hinted at the futuristic shape of engineering's latest gem, the Northrop Grumman X-47, more resembling a fighter in Battlestar Galactica than a traditional airplane. But also giant drones are under construction. They have a wing span the size of football fields, running on solar panels or hydrogen, capable of being in the air for weeks on end, akin to orbiting spies, but easier to operate. Another direction where research is heading is that of miniaturization, or if we want to use a word more in vogue, that of nanotechnology. In 2006 DARPA gave the green light to a research project with the aim to build a drone with the dimensions and performances of an insect, that is, weighing less than 10 grams, being shorter than 7,5 centimetres, capable of flying at 10 meters/second, with a range of action of one kilometre, and able to hover in the air for at least one minute.

A drone of this kind, other than its military uses, could also be used by the secret services and by the police, to spy or kill. Indeed it could function like smart bombs on a smaller scale. The microdrone would revolutionize all the systems of protection and would have no small consequences on politics and on society. Keep in mind that, in the near future, just as it could be in the hands of the police or the army, the mafia and terrorist groups could have it too. If today it is rather hard and risky for terrorists and mafias to try to kill a politician or some other eminent personality, with the aid of these microscopic flying robots it could become all too easy. It would be enough to remote control them with a SAT-NAV system to reach the victim. The microdrone could thus blow up near the head or other vital organs, or even, alternatively, kill the victim with a lethal injection or with a high voltage electric charge, and then fly off. If an almost invisible nanodrone were to be made, it could enter the nostrils or ears of the victim, killing it with a micro-explosion inside the skull, eluding and confusing the traditional system of protection. Indeed it would not be easy to identify the source, unless one had even more sophisticated electronic systems to monitor and intercept. Setting out to build ever more sophisticated systems of protection, that is, antidotes to nanotechnological weapons, seems therefore more important than putting the weapon itself on the market.

In a hitherto unprecedented situation of vulnerability, it could become all but unsuitable to have a public role in politics, media or entertainment - particularly if such a role is hostile to major powers, mafia or groups with a strong ideological identity. But keep in mind that any 'enlightened lunatic' - laying his hands on this kind of weapons system - could try to kill a famous or powerful 
person out of sheer envy or paranoia. Probably, other than systems ID, it would be fitting to prepare a rather rigorous system of traceability that will include satellite systems and systems of land spies able to intercept almost any nanodrone or microdrone in the air or on the ground.

Excessive alarmism could be premature or unfounded, because in history every weapon has had a shield able to stop it. When we went online for the first time and our computers were aggressed by the first viruses, some said that the Internet would never take off as a tool for the masses, because the very expensive hardware could be systematically destroyed by virulent software costing next to nothing. One had not taken antiviruses into account and one had not taken into account the fact that some software would have cost more than the hardware themselves. Of course, more than one user had his computer destroyed by a virus. But these annoying incidents have not taken down the system.

This is to say that the predictions that we are venturing here can only be pure speculation. The future that nanotechnology will generate cannot be foreseen in full. In 2007, when David Leigh, a researcher at the University of Edinburgh, managed to construct a 'nanomachine' the individual parts of which were of the dimension of a molecule, we understood that technology had suddenly projected us into a novel direction with unpredictable consequences. If historical eras are defined by materials (stone, copper, bronze, iron, plastic, etc.), then we have entered into the age of nanomaterials [28]. What will it bring us? Leigh could not tell: "It is a bit like when stone-age man made his wheel, asking him to predict the motorway" [33]. We have entered into a new world, but it is simply impossible to know which kind of world it will be. Any presumption to do so will therefore miss the mark.

The future will be a world of nanomachines, but also the world of androids. An android (or a humanoid) is a robot resembling a human and able to imitate many human behaviours; many designers hope that they will also be able to think and feel in ways analogous - even though not absolutely identical - to those of humans. Ian Pearson had defined 'androids' as machines that have a consciousness, linking the concept not so much to the anthropoid shape, as to the anthropoid mind. Scientists and engineers are already designing humanoid soldiers [18].

The military hopes that androids - whatever is meant by them - will be even better warriors than humans. When DARPA asked the military and scientists to indicate what role robots will play alongside humans, and then without them, in the near future, they replied in the following order: demining, recognisance, vanguard, logistic, and infantry. Oddly, air defence and driving vehicles, where their use is common, were mentioned only at the end. When they were asked to give a date when it will be possible to send humanoid robots to the battlefield instead of infantrymen, the military said 2025 and the scientists 2020. Robert Finkelstein, president of Robotic Technology Inc., finds these forecasts too optimistic and gives 2035 as the date when androids will first be sent to the front. In any case it is not a long time. Many readers of this book will still be among us to verify the prediction.

\section{Conclusions}

Since the world began, wars have been fought by 'mixed' armies under various flags: an alliance of humans, animals and machines on the one hand, against an alliance of humans, animals and machines on the other. This was the case in the days of Alexander the Great and it is the case today. The war machines that Archimedes or other Hellenistic engineers conceived are not as powerful as the robots we today send out to the battlefield, but still they are their cultural ancestors [5, pp. 124130]. To wonder if the Golem model will arrive is like asking: will this pattern change? The ongoing emergence of sophisticated objects that violate ordinary people's expectations as to how the world works or should work leads one to suspect that war as a whole could also yield some surprises. The greatest fear is that of seeing, for the first time in history, homogenous and no longer mixed deployments, namely: machines against humans. Science fiction and apocalyptic journalism insist on this matter. 
Any prediction, even when founded on rigorous studies of trends, always have a large speculative component by virtue of the complexity of the system. All the same, scenario analyses are still useful and therefore we will not shy away from venturing a prediction. All our analyses lead to the conclusion that the hypothesis of a 'species' war between humans and machines, ending with the defeat of the former, is highly unlikely in the $21^{\text {st }}$ century. The reasons underlying this belief are all in all six.

1) Metaphysical Uncertainty. One must consider first of all that it might be impossible for human consciousness to understand itself or replicate by scientific means. Even though materialistic metaphysics has shown itself most fecund to science in the last few centuries, and thereby made a privileged hypothesis, this does not allow us to exclude with absolute certainty the plausibility of idealistic or dualistic metaphysics. If the supporters of dualistic mind-matter ontology - like Pythagoras, Plato, René Descartes, Karl Popper, etc. - are correct, then robots can never be conscious in the same way as a human being.

2) The Complexity of Consciousness. Even if we postulate that materialistic metaphysics is correct, it is necessary to acknowledge how hard our task is. There has been remarkable progress in Logic, Computer Science, Psychiatry, Biology and Philosophy of Mind in the last centuries, but we are still a long way from understanding the concept of consciousness. And we cannot replicate what we do not understand. We can only make something different. In addition, considering that we have not yet managed to solve technical problems that are apparently simpler, such as a cure for baldness or caries, it is understandable that some previsions about the technological development of androids are regarded as overly optimistic.

3) The Alien Character of Artificial Consciousness. Even if we postulate that consciousness is just an emerging property of matter when suitably organized, and admit that artificial consciousness could emerge as an undesirable collateral effect from other actions, this does not imply that alien intelligence would necessarily be a hostile artificial intelligence. In other words, even if our machines were to spontaneously acquire their autonomy for reasons beyond our comprehension, this does not logically entail that they will be violent towards us. We tend to view humans as angels and machines as potential Terminators, but all anthropological and biological observations demonstrate that it is man in fact who is the most dangerous and aggressive predator produced by evolution. An alien intelligence could be benevolent precisely because it is alien, and not in spite of it. In other words, the alien character of artificial intelligence is in reality an argument against it being hostile. This is how things stand now until proven otherwise.

4) Potency of Technological Man. Even if a hostile artificial intelligence were to emerge, even if our robots were to rebel against us, humans are still powerful enough to engage in the equivalent of an 'ethnic cleansing' of the machines. Let us not forget that humans would not be fighting the robots with bows and arrows, but with blinded tanks, airplanes, remote controlled missiles, and, in extreme cases, nuclear devices. The battle would be between two hitherto unseen armies: on the one hand an alliance of manned systems and unmanned systems that have remained faithful to humans, and on the other hand unmanned systems remote controlled by hostile artificial intelligence. The final outcome of this hypothetical clash is anything but certain.

5) Evolution of Technological Man. Even if unmanned systems were to evolve to the point of becoming more potent than any manned system, we should not forget that humans themselves will presumably undergo an evolution by technological means. Humans, using genetic engineering or hybridising with machines via the implants of microchips in the brain or under the skin, could cease to be the weak link in the chain. In the future they might react at a thinking level equal in speed and precision to those of machines.

6) Man-Machine Hybridization. Finally we must consider that, because of technological development in the fields of bioengineering and of robotic engineering, we might never have a conflict between the organic and the inorganic worlds, between humans and machines, between carbon and silicon, simply because there will be a real and true ontological 'remixing.' There will be human beings empowered with electro-mechanical parts and robots with organic portions in their brain. Therefore it is not ontology that will decide the alliances. 
In conclusion, we believe that in the $21^{\text {st }}$ century there will still be humans, machines and animals serving under one national flag, waging war against humans, machines and animals serving under another national flag. When this system has disappeared, if there are still conflicts, in our opinion it will be more likely to see a variety of sentient beings (humans, transhumans, and posthumans) on the one hand, under one flag, against a variety of sentient beings (humans, transhumans, and posthumans), under another flag. But we are speaking of a very remote future.

The more concrete and pragmatic recommendation that I would now give makers of robotic weapons and their political and military customers is to always work on parallel projects, conceiving, for each robotic weapon that they construct, another weapon able to control and destroy it. This precaution could reveal itself useful both in the science fiction scenario of the emergence of hostile artificial intelligence, and in the more prosaic and plausible scenario that the robotic weapon falls into enemy hands.

However I believe it inopportune and irrational to apply the maximalist version of the precautionary principle. By maximalist version I mean an interpretation of 'precaution' that would mean banning any technology that does not present itself as absolutely risk-free. ${ }^{4}$ First of all, there is no technology or human action that is risk-free, because it is not possible to foresee the whole range of future developments inherent in a certain choice. As it is said, the flapping of a butterfly wing in the Southern Hemisphere can cause a hurricane in the Northern Hemisphere. Second, since we do not live in paradise and since processes pregnant with a future that we do not know are already in the making, non action does in no way guarantee that the results will be better for our group or for all humanity. This to say that the failure of the butterfly wing to flap in the Southern Hemisphere could also provoke an extremely serious drought in the Northern Hemisphere. Finally, the precautionary principle (at least in its maximalist interpretation) never pays sufficient attention to the benefits that might derive from a risky action. On closer inspection, fire has been a risky undertaking for Homo Erectus. During the million or maybe more years that separate us from the discovery of the technique of lighting and controlling fire, many forests and cities have been consumed by flames because of clumsy errors by our ancestors. Billions of living beings have probably died because of this technology. And today we still hear of buildings that burn or explode, causing deaths, because of malfunctioning central heating systems or mere forgetfulness.

Yet what would humans be without fire? If our ancestors had applied the maximalist precautionary principle, rejecting fire because it is not risk-free, today we would not be Homo Sapiens. This dangerous technology has indeed allowed us to cook our food and hence for hominid jawbone to shrink, with the ensuing development of language, and of the more advanced idea of morality and technology that language allows. In brief, today we would not even argue in favour or against the precautionary principle, or indeed any principle, because these require language for their formulation.

\section{References}

1. Ahmed, A. The Thistle and the Drone. How America's War on Terror Became a Global War on Tribal Islam, Washington D. C.: Brookings Institution Press, 2013.

2. Bashir, S., and R. D. Crews (eds.). Under the Drones. Modern Lives in the Afghanistan-Pakistan Borderlands, Cambridge (MA) and London: Harvard University Press, 2012.

3. Brown, A. War crimes and killer robots, The Guardian, March 18, 2009.

4. Campa, R. Kodeksy etyczne robotów: zagadnienie kontroli sprawowanej przez człowieka, Pomiary Automatyka Robotyka 3/2011, pp. 86-90.

5. Campa, R. La rivincita del paganesimo. Una teoria della modernità, Monza: Deleyva Editore, 2013.

6. Cappella, F. Big Dog, Neapolis, March 20, 2008.

7. Chomsky, N., and A. Vltchek. On Western Terrorism. From Hiroshima to Drone Warfare, London: Pluto Press, 2013. 
8. Clapper, J. R., J. J. Young, J. E. Cartwright, and J. G. Grimes. Unmanned Systems Roadmap 2007-2032, Department of Defense (USA), 2007.

9. Clapper, J. R., J. J. Young, J. E. Cartwright, and J. G. Grimes. Unmanned Systems Roadmap 2009-2034, Department of Defense (USA), 2009.

10. Devereux, T. La guerra elettronica: arma vincente 1812-1992, Varese: Sugarco Edizioni, 1993. 11. Evangelista, M., and H. Shue (eds.). The American Way of Bombing. Changing Ethical and Legal Norms, from Flying Fortresses to Drones, Ithaca and London: Cornell University Press, 2014.

12. Feletig, P. Robot per mare, per cielo e per terra ormai in guerra si va senza uomini. Repubblica, February 1, 2010.

13. Ishihara, K., and T. Fukushi. Introduction: Roboethics as an Emerging Field of Ethics of Technology, Accountability in Research 17 (6): Roboethics, 2010, pp. 273-277.

14. Kopacek, P. Roboethics, IFAC Proceeding Volumes 45 (10), 2012, pp. 67-72.

15. Maruccia, A. Era del Robot, umanità in pericolo, Punto Informatico, February 28, 2010.

16. Meggiato, R. EATR il robot vegetariano. Sviluppato il primo robot in grado di alimentarsi da sé con dei vegetali, Wired, July 16, 2010.

17. Merton, R. K. The unanticipated consequences of purposive social action, American Sociological Review 1, 1936, pp. 894-904.

18. Nath, V., and S. E. Levinson. Autonomous Military Robotics, Heidelberg: Springer, 2014.

19. Nichols, M. Italian firm to provide surveillance drone for U.N. in Congo, Reuters, August 1, 2013.

20. Northrop Grumman. X-47B UCAS Makes Aviation History...Again! Successfully Completes First Ever Autonomous Aerial Refueling Demonstration, retrieved from: www.northropgrumman.com (May 13, 2015).

21. Page, L. US war robots in Iraq 'turned guns' on fleshy comrades, The Register, April 11, 2008.

22. Petroni, A. M. Liberalismo e progresso biomedico: una visione positive, In R. Campa (ed.), Divenire. Rassegna di studi interdisciplinari sulla tecnica e il postumano, Vol. 2, Bergamo: Sestante Edizioni, 2009, pp. 9-43.

23. Poundstone, W. Prisoner's Dilemma, New York: Doubleday, 1992.

24. R. Z. Tecnologie inquietanti, il Pentagono studia robot da guerra che si nutrono di cadaveri, Tiscali Notizie, July 17, 2009.

25. Relke, D. M. A. Drones, Clones, and Alpha Babes. Retrofitting Star Trek's Humanism, Post9/11, Calgary: University of Calgary Press, 2006.

26. Rogers, A., and J. Hill. Unmanned. Drone Warfare and Global Security, London: Pluto Press, 2014.

27. Sanchez, M. Robots Take Center Stage in U.S. War in Afghanistan, Fox News, March 23, 2009. 28. Serreli, V., C. Lee, E. R. Kay, and D. Leigh. A molecular information ratchet, Nature 445, February 1, 2007, pp. 523-527.

29. Sharkey, N. Robot wars are a reality. Armies want to give the power of life and death to machines without reason or conscience, The Guardian, August 18, 2007.

30. Sharkey, N. Ground for discrimination. Autonomous Robot Weapons, RUSI Defence Systems, October, 2008, pp. 86-89.

31. Sharkey, N. The Ethical Frontiers of Robotics, Science 322 (5909), December 19, 2008, pp. 1800-1801.

32. Singer, P. W. Robots at War: The New Battlefield, The Wilson Quarterly, Winter 2009.

33. Singer, P. W. Wired for War: The Robotics Revolution and Conflict in the $21^{\text {st }}$ Century, New York: The Penguin Press, 2009.

34. Sloggett, D. Drone Warfare. The Development of Unmanned Aerial Conflict, Barnsley: Pen \& Sword Aviation, 2014.

35. Sparrow, R. Killer Robots, Journal of Applied Philosophy 24 (1), February 2007, pp. 62-77. 
36. Sullins, J. P. An Ethical Analysis of the Case for Robotic Weapons Arms Control, In Podins, K., Stinissen, J., and Maybaum M. (eds.), 5th International Conference on Cyber Conflict, Tallinn: NATO CCD COE Publications, 2013.

37. Turse, N. The Changing Face of Empire. Special Ops, Drones, Spies, Proxy Fighters, Secret Bases, and Cyber Warfare, New York: Dispatch Books, 2012.

38. Tzafestas, S. Roboethics: A Navigating Overview, Springer, Cham 2016.

39. University of Sheffield. Killer Military Robots Pose Latest Threat To Humanity, Robotics Expert Warns, ScienceDaily, February 28, 2008.

40. Veruggio, G. The EURON Roboethics Roadmap, "Humanoids'06": IEEE-RAS International Conference on Humanoid Robots, December 6, 2006, pp. 612-617.

41. Veruggio, G., and F. Operto. Roboethics: Social and Ethical Implications of Robotics, In B. Siciliano, and O. Khatib (eds.), Springer Handbook of Robotics, Berlin Heidelberg: Springer, 2008, pp. 1499-1524.

42. Weinberger, S. Armed Robots Still in Iraq, But Grounded, Wired, April 15, 2008.

43. Weiner, T. New Model Army Soldier Rolls Closer to Battle, New York Times, February 16, 2005.

44. Whittle, R. Predator. The Secret Origins of the Drone Revolution, New York: Henry Holt and Company, 2014.

45. Winnefeld, J. A., and F. Kendall. The Unmanned Systems Integrated Roadmap FY2011-2036, Department of Defence (USA), 2011.

46. Winnefeld, J. A. and F. Kendall. The Unmanned Systems Integrated Roadmap FY2013-2038, Department of Defence (USA), 2013.

47. Wittes, B. and G. Blum. The Future of Violence. Robots and germs, Hackers and Drones, New York: Basic Books, 2015.

48. Zaloga, S. J. Unmanned Aerial Vehicles. Robotic Air Warfare 2017-2007, Oxford and New York: Osprey Publishing, 2008.

49. Creato EATR, robot da guerra che può nutrirsi di carne: s'infiamma il dibattito sulla cyberetica," AdnKronos, 2009, August 21.

\section{Notes}

1. The United States is one of the most active nations at the cutting edge in the development and use of these technological products.

2. Rocket Propelling Grenade - a Soviet manufactured anti-tank grenade launching system.

3. Originally elaborated by Merrill Flood and Melvin Dresher at the RAND in 1950, the prisoner's dilemma was later formalized and given its present name by Albert W. Tucker [23].

4. On this problem we invite the reader to have a look at Petroni's Liberalismo e progresso biomedico: una visione positiva [22]. Even though he mainly focuses on biotechnologies, the article offers a detailed and convincing analysis of the precautionary principle. 